\title{
Correction to: Ocimum Sanctum Linn: A Potential Adjunct Therapy for Hyperhomocysteinemia-Induced Vascular Dementia
}

Jagadeesh Prasad Pasangulapati, Arun Reddy Ravula, Dinesh Reddy Kanala, Shanmukhi Boyina, Kiran Gangarapu, and Hemanth Kumar Boyina

\section{Correction to:}

Chapter 30 in: P. Vlamos (ed.), GeNeDis 2018, Advances in Experimental Medicine and Biology 1195, https://doi.org/10.1007/978-3-030-32633-3_30

In the original version of this book, Chapter 30 was inadvertently published by including one additional author Dinesh Kumar Bharatraj. His name has now been removed in this revised version of the book.

The updated online version of this chapter can be found at https://doi.org/10.1007/978-3-030-32633-3_30 